\title{
Elevated Serotonin IA Binding in Remitted Major Depressive Disorder: Evidence for a Trait Biological Abnormality
}

\author{
Jeffrey M Miller*1,2, Kathleen G Brennan', Todd R Ogden ${ }^{1,3}$, Maria A Oquendo ${ }^{1,2}$, Gregory M Sullivan ${ }^{1,2}$, \\ J John Mann ${ }^{1,2}$ and Ramin V Parsey ${ }^{1,2}$ \\ 'Department of Molecular Imaging and Neuropathology, New York State Psychiatric Institute, New York, NY, USA; '2Department of Psychiatry, \\ Columbia University, New York, NY, USA; ${ }^{3}$ Department of Biostatistics, Mailman School of Public Health, Columbia University, New York, \\ NY, USA
}

\begin{abstract}
Several biological abnormalities in major depressive disorder (MDD) persist during episode remission, including altered serotonin neurotransmission, and may reflect underlying pathophysiology. We previously described elevated brain serotonin IA (5-HT IA) receptor binding in antidepressant-naive (AN) subjects with MDD within a major depressive episode (MDE) compared with that in healthy controls using positron emission tomography (PET). In this study, we measured 5-HTIA receptor binding in unmedicated subjects with MDD during sustained remission, hypothesizing higher binding compared with that in healthy controls, and binding comparable with currently depressed AN subjects, indicative of a biological trait. We compared 5-HTIA binding potential $\left(\mathrm{BP}_{\mathrm{F}}\right)$ assessed through PET scanning with [ ' $\mathrm{C}$ ]WAY- 100635 in 15 subjects with recurrent MDD in remission for $\geqslant 12$ months and off antidepressant medication for $\geqslant 6$ months, 51 healthy controls, and 13 AN MDD subjects in a current MDE. Metabolite-corrected arterial input functions were acquired for the estimation of $\mathrm{BP}_{\mathrm{F}}$. Remitted depressed subjects had higher $5-\mathrm{HT} \mathrm{T}_{\mathrm{A}} \mathrm{BP}_{\mathrm{F}}$ compared with healthy controls; this group difference did not vary significantly in magnitude across brain regions. 5- $\mathrm{HT}_{I A} \mathrm{BP}_{\mathrm{F}}$ was comparable in remitted and currently depressed subjects. Elevated $5-\mathrm{HT}_{\text {IA }}$ BP level among subjects with remitted MDD appears to be a trait abnormality in MDD, which may underlie recurrent MDEs. Future studies should evaluate the role of genetic and environmental factors in producing elevated $5-\mathrm{HT}_{\mid \mathrm{A}} \mathrm{BP} \mathrm{F}_{\mathrm{F}}$ and MDD, and should examine whether $5-\mathrm{HT}_{I A} \mathrm{BP}_{\mathrm{F}}$ is a vulnerability factor to MDEs that could have a role in screening high-risk populations for MDD.

Neuropsychopharmacology (2009) 34, 2275-2284; doi:I0.1038/npp.2009.54; published online 20 May 2009
\end{abstract}

Keywords: depression; serotonin; 5-HTIA receptor; remission; PET; trait

\section{INTRODUCTION}

Biological abnormalities in major depressive disorder (MDD) that are trait phenomena may be more likely to be part of the etiology of MDD predisposing to recurrent episodes of major depression, in contrast to homeostatic mechanisms or stress responses occurring only during acute illness (Bhagwagar and Cowen, 2008). There is evidence of trait serotonergic abnormalities in MDD. Acute tryptophan depletion provokes depressive symptoms in remitted depressed subjects and in their relatives, an effect not seen in healthy controls (Ruhe et al, 2007). In addition, acute challenges with serotonergic agents, such as citalopram or fenfluramine, result in blunted neuroendo-

*Correspondence: Dr JM Miller, Department of Molecular Imaging and Neuropathology / Psychiatry, New York State Psychiatric Institute / Columbia University, I05I Riverside Drive 42, New York, NY, I0033, USA, Tel: + 212543 6528, Fax: + 2125436017 ,

E-mail: jm2233@columbia.edu

Received 14 January 2009; revised 23 April 2009; accepted 27 April 2009 crine responses in remitted depressed subjects (Bhagwagar et al, 2002, Flory et al, 1998).

The $5-\mathrm{HT}_{1 \mathrm{~A}}$ receptor is located on the soma and proximal dendrites of serotonergic neurons in the brainstem raphe nuclei, in which it serves as an auto-receptor, and postsynaptically in the cortex and terminal fields (Aghajanian and Sanders-Bush 2002). We have previously reported that during a major depressive episode (MDE), antidepressantnaive (AN) $\mathrm{MDD}$ subjects have higher $5-\mathrm{HT}_{1 \mathrm{~A}}$ receptor binding in vivo than healthy controls as assessed by positron emission tomography (PET; outcome measure binding potential $\left(\mathrm{BP}_{\mathrm{F}}\right)=B_{\text {avail }} / K_{\mathrm{D}}$ where $B_{\text {avail }}$ is the receptor density available for binding and $1 / K_{\mathrm{D}}$ is the affinity of radioligand) (Parsey et al, 2006d). This is consistent with reports of elevated $5-\mathrm{HT}_{1 \mathrm{~A}}$ brain receptors in animal models of depression, including $5-\mathrm{HT}_{1 \mathrm{~A}}$ elevations in mice bred for helplessness on the tail suspension test (Naudon et al, 2002), and hippocampal 5- $\mathrm{HT}_{1 \mathrm{~A}}$ elevations among behaviorally depressed cynomolgus macaques in a postmortem quantitative receptor autoradiography study (Shively et al, 2007), although a PET imaging 
study by this group using the outcome measure $\mathrm{BP}_{\mathrm{p}}$ showed discrepant findings (Shively et al, 2006). Studies of neuroendocrine responses to $5-\mathrm{HT}_{1 \mathrm{~A}}$ receptor agonists in MDD have been inconsistent (reviewed in Navines et al (2007). There are also discrepancies in PET imaging findings regarding $5-\mathrm{HT}_{1 \mathrm{~A}}$ abnormalities in MDD (Drevets et al, 1999, 2007; Hirvonen et al, 2008; Meltzer et al, 2004; Moses-Kolko et al, 2007b; Sargent et al, 2000); divergent findings may be partly related to methodological differences and patient samples (see the Discussion section for further details). Postmortem studies of 5- $\mathrm{HT}_{1 \mathrm{~A}}$ receptor binding in depression and/or suicide have variously reported increases, no changes, or decreases (reviewed in Stockmeier (2003); see also Boldrini et al (2008)). To our knowledge, no postmortem study has examined $5-\mathrm{HT}_{1 \mathrm{~A}}$ receptor binding among subjects with remitted depression.

A previous PET study found persistent $5-\mathrm{HT}_{1 \mathrm{~A}}$ receptor abnormalities during remission from MDD among 14 male subjects compared with 18 controls using the outcome measure $\mathrm{BP}_{\mathrm{ND}}$ (Bhagwagar et al, 2004). In this study, we assessed $5-\mathrm{HT}_{1 \mathrm{~A}}$ binding among 15 remitted depressed subjects using cerebellar white matter as the reference region to estimate the outcome measure $\mathrm{BP}_{\mathrm{F}}$. On the basis of our findings among currently depressed subjects, we hypothesized that $5-\mathrm{HT}_{1 \mathrm{~A}} \mathrm{BP}_{\mathrm{F}}$ would be higher in those with recurrent MDD in sustained remission compared with that in healthy controls, consistent with a trait abnormality. As a secondary aim, we hypothesized that $5-\mathrm{HT}_{1 \mathrm{~A}} \mathrm{BP}_{\mathrm{F}}$ would not differ significantly between subjects with MDD in sustained remission and AN subjects with MDD in a current MDE.

In an exploratory manner, we genotyped subjects for a functional C-1019G promoter polymorphism of the $5-H T_{1 A}$ gene (Lemonde et al, 2003). The $\mathrm{G}$ allele has been associated with greater expression in raphe neuron cell cultures in vitro (Lemonde et al, 2003), with greater raphe nucleus binding in vivo (Parsey et al, 2006d), with the diagnosis of MDD, and with diminished response to antidepressant treatment (Le François et al (2008). Therefore, although this study was underpowered for genetic analyses, we explored the hypothesis that the $G$ allele would be less frequent among remitted MDD subjects compared with current MDD subjects, among whom only a portion will eventually achieve remission.

\section{MATERIALS AND METHODS}

\section{Subjects}

Fifteen subjects who met criteria for MDD in full remission, 51 healthy controls, and 13 AN currently depressed subjects with MDD were included in this study. This study draws on PET data from 42 healthy controls and 13 AN currently depressed MDD patients from a previous study (Parsey et al, 2006d); those subjects underwent PET scanning between 29 July 1999 and 25 March 2003. In this study, 15 subjects with MDD in full remission and a second cohort of 9 healthy controls underwent PET scanning with $\left[{ }^{11} \mathrm{C}\right]$ WAY-100635 to quantify $5-\mathrm{HT}_{1 \mathrm{~A}}$ receptor binding. Remitted depressed subjects were scanned between 3 February 2004 and 11 December 2007; the second cohort of controls was scanned between 24 May 2000 and 2 October
2007. Clinical assessments, PET acquisition, reconstruction, and image processing did not differ between groups. There was no evidence of drift in PET camera performance over the study period based on quality control measurements, including cross-calibration factor (in this assay, which is performed bimonthly, the HR + scanner is calibrated using a cylindrical phantom filled with ${ }^{18} \mathrm{~F}$. The phantom is scanned using the $\mathrm{HR}+$ for $30 \mathrm{~min}$. Ten samples of the activity $(2 \mathrm{ml}$ each) are taken from the phantom and measured in a Wallac 1480 Wizard well counter (PerkinElmer Lifescience). The cross-calibration factor is the ratio of detected counts between the scanner and the well counter). After a comparison of first and second cohorts of healthy controls showed no differences in $5-\mathrm{HT}_{1 \mathrm{~A}} \mathrm{BP}_{\mathrm{F}}$ considering all regions of interest (ROIs) $(\mathrm{F}=0.38, \mathrm{df}=1.49, p=0.54)$, these cohorts were combined in subsequent analyses. Subjects were recruited through community advertisements; remitted depressed subjects were already in remission at the time of recruitment. Eligibility was assessed by psychiatric and medical history, chart review, SCID, (Structured Clinical Interview for DSM-IV) (First et al, 1995), physical examination, routine blood tests, pregnancy test, and urine toxicology. The Beck Depression Inventory (BDI) (Beck et al, 1961), Hamilton Depression Rating Scale (HAM-D) (Hamilton, 1960), GAS (Global Assessment Scale) (Endicott et al, 1976), and Beck Hopelessness Scale (Beck et al, 1974), assessed depression severity and functional impairment.

Inclusion criteria for remitted depressed subjects were (1) DSM-IV criteria for MDD, in full remission for at least 1 year; $(2) \geqslant 2$ previous MDEs; (3) 17-item HAM-D $<8$ on screening; (4) absence of psychotropic medication use for $\geqslant 6$ months before the PET scan (to minimize the effects of previous antidepressant treatment on $5-\mathrm{HT}_{1 \mathrm{~A}} \mathrm{BP}_{\mathrm{F}}$ (Parsey et al, 2006d; Spindelegger et al, 2008)); (5) age 18-65 years; (6) no current or lifetime history of alcohol or other drug abuse or dependence; (7) absence of lifetime exposure to 3,4-methylenedioxymethamphetamine; (8) absence of significant current medical conditions; (9) absence of pregnancy; and (10) capacity to provide informed consent. We required a minimum of two previous MDEs, given findings of greater biological abnormalities in recurrent as opposed to single-episode MDD (Basso and Bornstein, 1999; Kupfer et al, 1991; Thase, 1992; Thase et al, 1995), with at least one difference persisting into remission (Jindal et al, 2002). Healthy controls met inclusion criteria (5)-(10), had no psychiatric history, and had no history of a mood or psychotic disorder in their first-degree relatives. AN subjects with current MDD met DSM-IV criteria for a current MDE and had never taken antidepressant medication; these subjects met inclusion criteria (5)-(10) mentioned above. Comorbid disorders among remitted depressed subjects, which were in remission, included post-traumatic stress disorder $(n=1)$ and attention-deficit hyperactivity disorder $(n=1)$. Among AN currently depressed subjects, comorbid disorders included panic disorder $(n=4)$, post-traumatic stress disorder $(n=2)$, dysthymia $(n=3)$, and social anxiety disorder $(n=1)$. This study was approved by the Institutional Review Board of the New York State Psychiatric Institute. All subjects gave written informed consent after explanation of the study. 


\section{Radiochemistry}

$\left[{ }^{11} \mathrm{C}\right]$ WAY-100635 was prepared as previously described (Parsey et al, 2000). Remitted depressed subjects had lower mean injected dose and mass of $\left[{ }^{11} \mathrm{C}\right] \mathrm{WAY}-100635$ compared with healthy controls (injected dose: remitted depressed $=4.6 \pm 1.2 \mathrm{mCi}$, controls $=8.0 \pm 3.4 \mathrm{mCi}, t=3.75$, $\mathrm{df}=64, \quad p=0.0004$; injected mass: remitted depressed $=1.7 \pm 1.6 \mu \mathrm{g}$, controls $=2.0 \pm 2.0 \mu \mathrm{g}, t=2.17, \mathrm{df}=64$, $p=0.033$ ). This was intentional, as the majority of remitted depressed subjects were scanned after the publication of a dosimetry study for $\left[{ }^{11} \mathrm{C}\right] \mathrm{WAY}-100635$ recommending reductions in injected dose and mass for human studies (Parsey et al, 2005b). [ $\left.{ }^{11} \mathrm{C}\right] \mathrm{WAY}-100635$ equilibrium distribution volume $\left(V_{\mathrm{T}}\right)$ should be insensitive to changes in injected mass if the receptor occupancy is below $10 \%$ (Slifstein and Laruelle, 2001). Indeed, there was no significant correlation between injected mass or dose and $V_{\mathrm{T}}$ in any ROI (representative pre- and post-synaptic regions: raphe nucleus and injected mass: $r=0.075$, $p=0.51$; raphe nucleus and injected dose: $r=0.025$, $p=0.82$; hippocampus and injected mass: $r=0.14$, $p=0.20$; hippocampus and injected dose: $r=0.11, p=0.36$ ).

Measurement of the arterial input function, plasma-free fraction $\left(f_{\mathrm{P}}\right)$, and metabolites was conducted as described previously (Parsey et al, 2000). $f_{P}$ was lower among remitted depressed than controls, but did not differ between remitted depressed and AN currently depressed subjects (remitted depressed $=0.062 \pm 0.026$, controls $=0.081 \pm 0.024, t=2.66$, $\mathrm{df}=64, p=0.01 ; \mathrm{AN}$ currently depressed $=0.066 \pm 0.023$; remitted vs AN currently depressed: $t=0.46, \mathrm{df}=26$, $p=0.65)$.

\section{PET and MRI Acquisition}

After placement of an arterial and venous catheter, PET imaging was performed on an ECAT EXACT HR + (Siemens/CTI, Knoxville, TN) (63 slices covering an axial field of view of $15.5 \mathrm{~cm}$, axial sampling of $2.46 \mathrm{~mm}$, in a three-dimensional (3D) mode. A 10-min transmission scan was acquired before injection of $\left[{ }^{11} \mathrm{C}\right] \mathrm{WAY}-100635$ as an intravenous bolus over $45 \mathrm{~s}$. Emission data were collected for $110 \mathrm{~min}$ as 20 successive frames of increasing duration. Images were reconstructed using the 3D-RP algorithm implemented on a vector processor $(\mathrm{CTI})$ to a $128 \times 128$ matrix (pixel size of $1.7 \times 1.7 \mathrm{~mm}^{2}$ ) with attenuation correction and a Shepp 0.5 filter (cutoff 0.5 cycles/ projection rays) resulting in an in-plane and axial resolution (ie, full-width half-maximum) of 4.4 and $4.1 \mathrm{~mm}$ in air and at the center of the field of view (Brix et al, 1997). Scatter correction was performed using the technique implemented by the manufacturer (Watson et al, 1995).

Acquisition of $T_{1}$-weighted MRI for co-registration of PET images and identification of ROIs was performed as previously described using a $1.5 \mathrm{~T}$ Signa Advantage or a $3 \mathrm{~T}$ Signa HDx system (General Electric Medical Systems, Milwaukee, WI) (Parsey et al, 2000).

\section{Image Analysis}

Image analysis was performed using MATLAB 2006b (The Mathworks, Natick, MA) with extensions to the following open source packages: Functional Magnetic Resonance Imaging of the Brain's Linear Image Registration Tool (FLIRT) v5. (Jenkinson and Smith, 2001), Brain Extraction Tool (BET) v1.2 (Smith, 2002), as well as Statistical Parametric Mapping (SPM5) normalization (Ashburner and Friston, 1999) and segmentation routines (Ashburner and Friston, 2005). No attempt was made to correct for transmission-emission mismatch. To correct for subject motion, de-noising filter techniques were applied to all PET images starting at frame five. The eighth frame was used as a reference to which all other frames were aligned using rigid body FLIRT. Motion correction was assessed visually by comparing movies of pre- and post-motion correction scans. Motion was evaluated for drift between frames and across the entire scan duration, separately. A mean of motion corrected frames 8-18 for each subject was registered to that subject's $T_{1}$-weighted MRI using FLIRT.

ROIs were hand drawn on individual subjects' $T_{1}$-weighted MRI images by experienced technicians trained to reliably approximate these regions using brain atlases (Duvernoy, 1991; Talairach and Tournoux, 1988) and published reports (Kates et al, 1997; Killiany et al, 1997). ROIs included the ventral prefrontal cortex (PFC), medial PFC, dorsolateral PFC, anterior cingulate, body of the cingulate (posterior to anterior cingulate), amygdala, hippocampus, parahippocampal gyrus, insular cortex, temporal cortex, parietal cortex, and occipital cortex. A fixed volume elliptical ROI $\left(2 \mathrm{~cm}^{3}\right)$ was placed on the raphe nuclei in the dorsal midbrain; a composite of mostly the dorsal and median raphe nuclei on a mean PET image for each subject as the boundaries of this structure cannot be identified on MRI. A cylindrical ROI was drawn in the cerebellar white matter, which was used as the reference region for this study, as it has been previously shown to have the lowest concentration of $5-\mathrm{HT}_{1 \mathrm{~A}}$ receptors within the cerebellum, and is adequately modeled by a one-tissue compartment model (Parsey et al, 2005a). For comparison purposes, a cylindrical ROI was drawn in the cerebellar gray matter. The segmented MRI image was used to refine the contours of the ROI to more accurately reflect the gyral pattern and differences between the PET and MRI fields of view.

\section{Quantitative Analysis}

Regional distribution volumes of $\left[{ }^{11} \mathrm{C}\right] \mathrm{WAY}-100635$ were derived from kinetic analysis using the arterial input function and a two-tissue compartment (2T) model as the general framework (for details see Parsey et al, 2000). $V_{\mathrm{ND}}$ and $V_{\mathrm{S}}$ are defined as the distribution volumes of the non-displaceable and specific compartments, respectively (Laruelle et al, 1994; Mintun et al, 1984). $V_{\mathrm{T}}$, the total regional equilibrium distribution volume, is equal to $V_{\mathrm{ND}}+$ $V_{\mathrm{S}}$. The primary outcome measure for this study was binding potential $\left(\mathrm{BP}_{\mathrm{F}}=B_{\text {avail }} / K_{\mathrm{D}}\right)$. Time-activity curves were fit with a $2 \mathrm{~T}$ model, which has the $K_{1} / k_{2}$ ratio fixed to that of the cerebellar white matter (reference region). $\mathrm{BP}_{\mathrm{F}}$ was calculated as $\left(V_{\mathrm{T}(\mathrm{ROI})}-V_{\mathrm{T}(\mathrm{CER})}\right) / f_{\mathrm{P}}$ or $\left(V_{\mathrm{T}}-V_{\mathrm{ND}}\right) / f_{\mathrm{P}}$. For comparison purposes, the outcome measure, $\mathrm{BP}_{\mathrm{ND}}$, was calculated using the simplified reference tissue model (SRTM) (Lammertsma and Hume, 1996) using both the cerebellar white and gray matter, as was the outcome 
measure $\mathrm{BP}_{\mathrm{P}}\left(=V_{\mathrm{T}}-V_{\mathrm{ND}}=f_{\mathrm{p}} B_{\text {avail }} / K_{\mathrm{D}}\right)$. The contribution of plasma total activity to regional activity was calculated assuming a $5 \%$ blood volume in the ROI and was subtracted before analysis. Kinetic parameters were derived by nonlinear regression using the Levenberg-Marquart least squares minimization procedure implemented in MATLAB (The Math Works Inc., South Natick, MA).

\section{Genotyping}

Genotyping of the C(-1019)G polymorphism of the $5-H T_{1 A}$ receptor gene was performed using allele-specific PCR amplification as previously described (Parsey et al, 2006d).

\section{Statistical Analysis}

To properly account for correlations among measurements made on the same subject, we applied mixed-effects modeling methods and analyzed the data for the 13 regions simultaneously, with region and diagnostic group as fixed effects and subject as the random effect. SEs were computed for each estimated $\mathrm{BP}_{\mathrm{F}}$ value using a bootstrap algorithm that takes into account errors in the metabolite, plasma, and brain data (Ogden and Tarpey, 2006). Observations were weighed accordingly in the linear mixed-effects models to increase precision in group estimates. Analyses were performed on natural log-transformed values. Log transformation is commonly used to remedy problems with skewness and unequal variance, both of which are generally issues with PET data. It has specifically been used in previous PET studies by our group and others to address these issues (Hirvonen et al, 2008; Miller et al, 2008; Oquendo et al, 2007; Parsey et al, 2006a,b, c, d; Sullivan et al, 2005). Other groups have used related statistical approaches, including linearizing transformation (Rabiner et al, 2002b) and non-parametric testing (Meltzer et al, 2004) to address these issues in analyzing PET data. As the natural $\log$ is a monotone transformation, demonstrating a difference in $\log \left(\mathrm{BP}_{\mathrm{F}}\right)$ is equivalent to demonstrating a difference (in the same direction) in $\mathrm{BP}_{\mathrm{F}}$. Figure 1 presents raw $\mathrm{BP}_{\mathrm{F}}$ values. Reported $p$-values were not adjusted for multiple comparisons. Linear mixed-effects models of binding and Fisher's exact tests were performed in $\mathrm{R}$ 2.1.0 (http://www.cran.r-project.org). $t$-tests were performed in Excel (Microsoft, 2003).

\section{RESULTS}

\section{Clinical Characteristics}

Clinical characteristics of the study sample are presented in Table 1. The remitted MDD group had depression severity ratings that were modestly greater than those of the healthy volunteers and only $10 \%$ that of the acutely depressed MDD group for the BDI. Both MDD groups had a comparable number of previous MDEs; the remitted group had been free from an episode for a mean of 3 years at the time of study participation. About $60 \%$ of both MDD groups had a first-degree relative with MDD. Clinical assessments reported in this study were obtained within an average of $3.7 \pm 5.2$ days of PET scanning.

\section{Comparison of 5- $\mathrm{HT}_{1 \mathrm{~A}} \mathrm{BP}_{\mathrm{F}}$ Between Groups}

Remitted depressed subjects had higher $5-\mathrm{HT}_{1 \mathrm{~A}} \mathrm{BP}_{\mathrm{F}}$ compared with healthy controls, including all brain regions in the model (Figure $1 ; \mathrm{F}=4.99, \mathrm{df}=1.90, p=0.028$ ). As we have found an inverse relationship between aggression (BrownGoodwin Aggression scale) and $5-\mathrm{HT}_{1 \mathrm{~A}} \mathrm{BP}_{\mathrm{F}}$, as well as a sex effect, with higher $5-\mathrm{HT}_{1 \mathrm{~A}} \mathrm{BP}_{\mathrm{F}}$ among women (Parsey et al, 2002), sex and aggression scores were included as covariates in linear mixed-effects models. The difference between remitted depressed subjects and healthy controls remained statistically significant with inclusion of sex and aggression as covariates in the model $(\mathrm{F}=8.45, \mathrm{df}=1.86, p=0.0046)$. The magnitude of difference between these groups did not vary across the brain regions examined (region-by-diagnosis interaction: $\mathrm{F}=1.36, \mathrm{df}=12.756, p=0.18$ ).

$5-\mathrm{HT}_{1 \mathrm{~A}} \mathrm{BP}_{\mathrm{F}}$ did not differ between remitted MDD and AN acutely depressed MDD subjects (Figure 1; F $=0.065$, $\mathrm{df}=1.90, \quad p=0.80)$, even after inclusion of sex and aggression as covariates in the model $(\mathrm{F}=0.003, \mathrm{df}=1.86$, $p=0.95)$. $5-\mathrm{HT}_{1 \mathrm{~A}} \mathrm{BP}_{\mathrm{F}}$ was higher among AN acutely depressed MDD subjects than in the combined cohort of healthy controls $(\mathrm{F}=6.65, \mathrm{df}=1.62, p=0.012)$, even after inclusion of sex and aggression as covariates in the model $(\mathrm{F}=7.51, \mathrm{df}=1.58, p=0.0081)$.

\section{Alternative Outcome Measures}

To compare our findings with other studies, we repeated the primary analysis comparing remitted depressed subjects with healthy controls using the outcome measure $\mathrm{BP}_{\mathrm{ND}}$, estimated by the simplified reference tissue method (Slifstein et al, 2000), consistent with methods used in a previous publication examining $5-\mathrm{HT}_{1 \mathrm{~A}}$ binding in remitted depression (Bhagwagar et al, 2004). We performed this comparison using two different reference regions, cerebellar white matter and cerebellar gray matter. When using the cerebellar white matter as the reference region, $\mathrm{BP}_{\mathrm{ND}}$ was an average of $11.4 \%$ higher across all ROIs among remitted depressed subjects than controls, although this difference was not statistically significant $(\mathrm{F}=1.66, \mathrm{df}=1.61$, $p=0.20$ ). In contrast, when the cerebellar gray matter was used as the reference region, which has appreciable $5-\mathrm{HT}_{1 \mathrm{~A}}$ binding (Parsey et al, 2005a), $\mathrm{BP}_{\mathrm{ND}}$ was an average of $22.6 \%$ lower across all ROIs among remitted depressed subjects than controls $(\mathrm{F}=10.78 \mathrm{df}=1.61, p=0.002)$. Although the $V_{\mathrm{T}}$ of the reference region used for our primary analyses, the cerebellar white matter, did not differ significantly between remitted depressed and control subjects (remitted depressed: $0.25 \pm 0.10$, controls: $0.29 \pm 0.11, t=1.16$, $\mathrm{df}=64$, $p=0.25$ ), there was a trend toward higher $V_{\mathrm{T}}$ in the alternative reference region of cerebellar gray matter among remitted depressed subjects compared with controls (remitted depressed: $0.57 \pm 0.25$, controls: $0.47 \pm 0.19, t=1.71$, $\mathrm{df}=64, p=0.092$ ).

When we re-analyzed our data using the outcome measure $\mathrm{BP}_{\mathrm{P}} \quad\left(=V_{\mathrm{T}}-V_{\mathrm{ND}}=f_{\mathrm{p}} B_{\text {avail }} / K_{\mathrm{D}}\right)$, which requires the assumption of equivalent $f_{\mathrm{P}}$ between groups, but which therefore does not require $f_{\mathrm{P}}$ measurement, using cerebellar white matter as the reference region, differences in $5-\mathrm{HT}_{1 \mathrm{~A}}$ $\mathrm{BP}_{\mathrm{P}}$ between remitted depressed subjects and controls were not statistically significant $(\mathrm{F}=0.38, \mathrm{df}=1.64, p=0.54)$. 


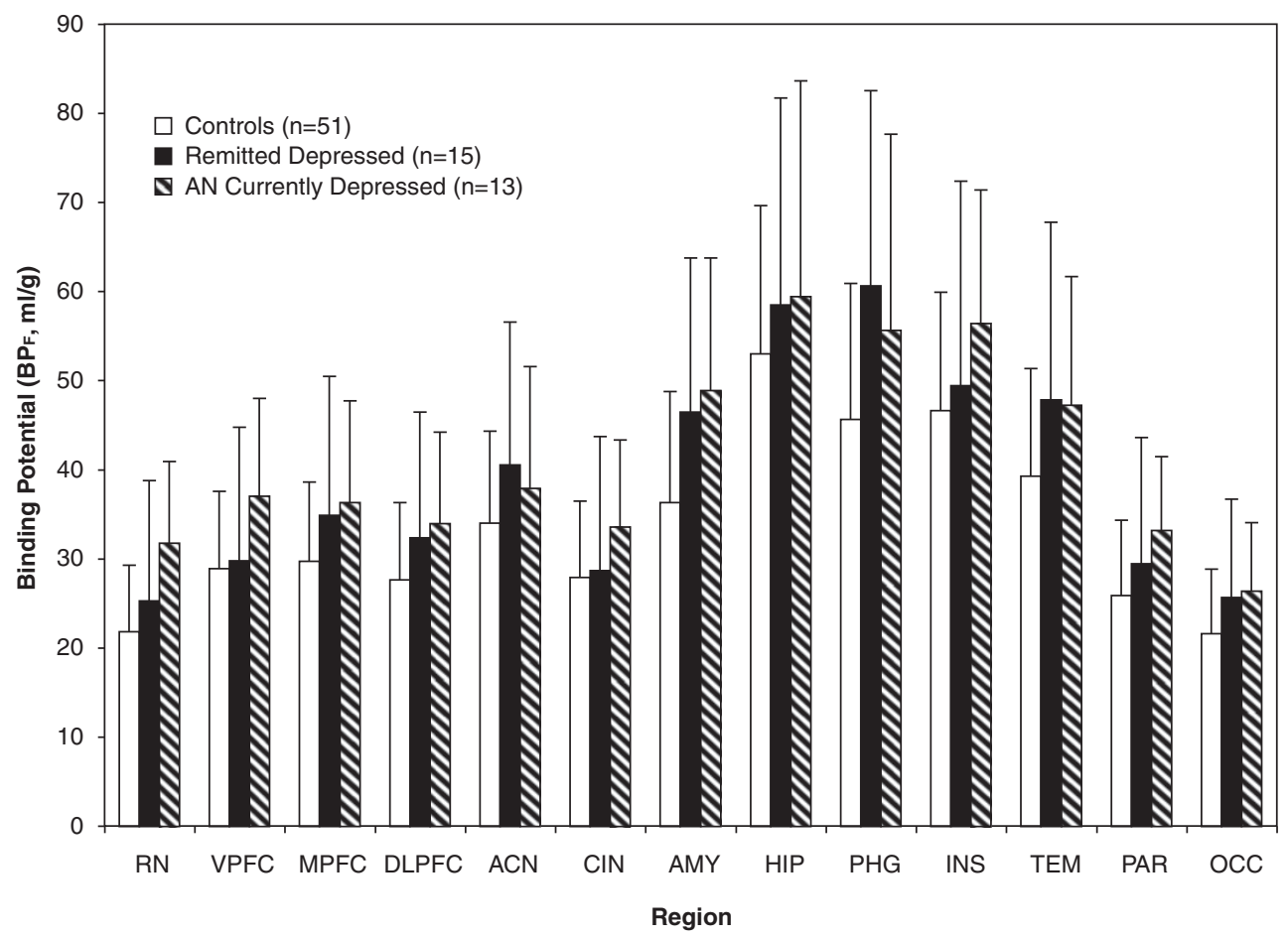

Figure I Remitted depressed subjects have higher serotonin IA receptor binding potential $\left(\mathrm{BP}_{\mathrm{F}}\right)$ than healthy controls and do not differ significantly from antidepressant-naive currently depressed subjects, considering all regions simultaneously. Regions: RN, raphe nuclei; VPFC, ventral prefrontal cortex; MPFC, medial PFC; DLPFC, dorsolateral PFC; ACN, anterior cingulate; CIN, cingulate cortex (posterior to ACN); AMY, amygdala; HIP, hippocampus; PHG, parahippocampal gyrus; INS, insular cortex; TEM, temporal cortex; PAR, parietal cortex; OCC, occipital cortex. The linear mixed-effects model comparing remitted depressed to controls is $\mathrm{F}=4.99, \mathrm{df}=1.90, p=0.028$; comparing remitted depressed to currently depressed is $\mathrm{F}=0.065, \mathrm{df}=1.90, p=0.80 . \mathrm{Bar}$ heights indicate weighted mean $\mathrm{BP}_{\mathrm{F}}$ for each $\mathrm{ROI}$; error bars represent the corresponding equivalent of the $\mathrm{SD}$ of the weighted mean for each $\mathrm{ROI}$.

\section{5-HT $1 \mathrm{~A}$ Receptor Promoter Polymorphism}

For genetic analysis, we included antidepressant exposed with antidepressant-naive currently depressed subjects from the currently depressed MDD cohort (described in Parsey et al, 2006d), as previous medication status does not affect genotype, comparing these 28 currently depressed subjects with remitted depressed subjects and healthy volunteers for the $\mathrm{C}(-1019) \mathrm{G}$ polymorphism in the $5-H T_{1 A}$ receptor gene. Considering all three groups simultaneously (healthy controls, remitted MDD, and currently depressed MDD), there was a difference in genotype between groups, with higher frequency of the GG genotype in the MDD groups (Table 2; Fisher's exact test, $p=0.019$ ). In pair-wise group comparisons of genotype frequency, the only two groups that differed significantly in genotype were currently depressed and control groups (Fisher's exact test, $p=0.005$ ); there were not significant differences between controls and remitted depressed (Fisher's exact, $p=0.54$ ) or between remitted depressed and currently depressed groups (Fisher's exact, $p=0.23$ ). The $\mathrm{G}$ allele was similarly more frequent in the current MDD group than in the control group (Fisher's exact, $p=0.038$ ).

\section{DISCUSSION}

We find higher $5-\mathrm{HT}_{1 \mathrm{~A}} \mathrm{BP}_{\mathrm{F}}$ across all studied brain regions in subjects with recurrent MDD in sustained remission and who were off antidepressant medications for at least 6 months compared with that in healthy controls. In addition, we do not find a significant difference in $5-\mathrm{HT}_{1 \mathrm{~A}} \mathrm{BP}_{\mathrm{F}}$ between remitted and currently depressed MDD subjects. These findings are consistent with a trait abnormality in $5-\mathrm{HT}_{1 \mathrm{~A}}$ receptor $\mathrm{BP}_{\mathrm{F}}$ in $\mathrm{MDD}$.

Although the current findings may appear at odds with a report of lower 5- $\mathrm{HT}_{1 \mathrm{~A}} \mathrm{BP}_{\mathrm{ND}}$ among remitted depressed subjects compared with controls (Bhagwagar et al, 2004), that study used the entire cerebellum as the reference region, and estimated the outcome measure $\mathrm{BP}_{\mathrm{ND}}$. Inclusion of the cerebellar vermis and gray matter in a reference region may lead to bias in resulting binding estimates, given the detectable $5-\mathrm{HT}_{1 \mathrm{~A}}$ binding in these subregions (Parsey et al, 2005a). Small differences in the reference region distribution volume $\left(V_{\mathrm{ND}}\right)$ can have large effects on $\mathrm{BP}_{\mathrm{ND}}$, as $\mathrm{BP}_{\mathrm{ND}}$ is equal to $\left(V_{\mathrm{T}}-V_{\mathrm{ND}}\right) / V_{\mathrm{ND}}$, and $V_{\mathrm{ND}}$ is typically $<1$. When we re-analyzed our data using the cerebellar gray matter as the reference region, estimating $\mathrm{BP}_{\mathrm{ND}}$ using SRTM, $\mathrm{BP}_{\mathrm{ND}}$ was an average of $22.6 \%$ lower across all ROIs among remitted depressed subjects than controls, consistent with the findings of Bhagwagar et al (2004). In contrast, when $\mathrm{BP}_{\mathrm{ND}}$ was estimated using the cerebellar white matter as the reference region, mean $\mathrm{BP}_{\mathrm{ND}}$ was $11.4 \%$ higher across all ROIs among remitted depressed subjects than controls, although this difference was not statistically significant. This difference was driven by a trend toward higher $V_{\mathrm{T}}$ in the alternative reference region of cerebellar gray matter among remitted depressed subjects compared with controls, consistent with our reports of appreciable $5-\mathrm{HT}_{1 \mathrm{~A}}$ receptor 
Table I Clinical and Demographic Characteristics of the Sample

\begin{tabular}{|c|c|c|c|c|c|}
\hline Continuous variables & $\begin{array}{l}\text { Controls } \\
(n=51)\end{array}$ & $\begin{array}{c}\text { Remitted } \\
\text { depressed } \\
(n=15)\end{array}$ & $\begin{array}{c}\text { Antidepressant-naive } \\
\text { (AN) currently depressed } \\
(n=13)\end{array}$ & $\begin{array}{l}\text { Remitted } \\
\text { depressed } \\
\text { vs controls }\end{array}$ & $\begin{array}{c}\text { Remitted depressed } \\
\text { vs AN currently } \\
\text { depressed }\end{array}$ \\
\hline Age & $37.4 \pm 14.5$ & $31.8 \pm 10.9$ & $35.9 \pm 12.3$ & 0.17 & 0.36 \\
\hline 24-Item Hamilton depression rating scale & $0.7 \pm 1.0$ & $3.5 \pm 2.3$ & $25.5 \pm 8.0$ & $<0.0001$ & $<0.0001$ \\
\hline Global assessment scale & $90.1 \pm 4.6$ & $86.3 \pm 7.5$ & $52.5 \pm 12.8$ & 0.02 & $<0.0001$ \\
\hline Beck hopelessness scale & $1.7 \pm 2.3$ & $2.5 \pm 2.4$ & $9.6 \pm 6.1$ & 0.21 & 0.0003 \\
\hline Brown-Goodwin aggression scale & $13.6 \pm 4.1$ & $|8 . \pm 4|$. & $16.3 \pm 4.6$ & 0.0006 & 0.3 \\
\hline Years of education & $16.6 \pm 2.9$ & $16.1 \pm 1.0$ & $13.3 \pm 4.2$ & 0.49 & 0.02 \\
\hline Age at onset & $N / A$ & $15.9 \pm 4.8$ & $22.1 \pm 11.4$ & N/A & 0.069 \\
\hline Categorical variables & \multicolumn{2}{|l|}{$N(\%)$} & \multicolumn{3}{|c|}{$p$-value (fisher's exact) } \\
\hline Female & $29(56.9)$ & $10(66.7)$ & $10(76.9)$ & 0.56 & 0.69 \\
\hline Subjects with a history of previous suicide attempts & $0(0)$ & $2(13.3)$ & $4(30.8)$ & 0.049 & 0.37 \\
\hline $\begin{array}{l}\text { Subjects with a history of major depression in first- } \\
\text { degree relatives }\end{array}$ & $0(0)$ & $9(60)$ & $8(61.5)$ & $<0.0001$ & I \\
\hline Race/ethnicity & & & & 0.035 & 0.0006 \\
\hline Asian & $7(13.7)$ & $0(0)$ & $0(0)$ & & \\
\hline African American & $8(15.7)$ & । (6.7) & । (7.7) & & \\
\hline Caucasian & $28(54.9)$ & $13(86.7)$ & $4(30.8)$ & & \\
\hline Hispanic & $8(15.7)$ & $0(0)$ & $7(53.8)$ & & \\
\hline
\end{tabular}

${ }^{a} p$-value associated with non-parametric Mann-Whitney test as some subjects reported 'too numerous to count' before depressive episodes.

Table 2 Genotypic and Allelic Frequencies of the C(-1019)G Polymorphism in the 5-HT IA $_{\text {Receptor Gene }}$

\begin{tabular}{|c|c|c|c|c|c|c|}
\hline & \multirow[b]{2}{*}{$n$} & \multicolumn{3}{|c|}{ Genotypes n (\%) } & \multicolumn{2}{|c|}{ Alleles $n$ (\%) } \\
\hline & & CC & CG & GG & C & G \\
\hline Controls & $50^{\mathrm{a}}$ & $17(34)$ & $29(58)$ & $4(8)$ & $49(59.8)$ & $33(40.2)$ \\
\hline Remitted MDD & $14^{a}$ & $3(21.4)$ & $9(64.3)$ & $2(14.3)$ & $15(53.6)$ & $13(46.4)$ \\
\hline Current MDD & 28 & $6(21.4)$ & II (39.3) & II (39.3) & $23(41.1)$ & $33(58.9)$ \\
\hline
\end{tabular}

${ }^{\mathrm{a} O n e}$ control and one remitted MDD subject were not genotyped.

binding in the cerebellar gray matter (Parsey et al, 2005a). This result reconciles seemingly disparate findings, and emphasizes the importance of considering specific methodology, including the reference region and outcome measure used, in interpreting PET findings (Parsey et al, 2000).

We used $\mathrm{BP}_{\mathrm{F}}$ as the outcome measure in this study as it is the closest measure to $B_{\text {avail }}$ among the existing outcome measures for PET studies $\left(\mathrm{BP}_{\mathrm{F}}, \mathrm{BP}_{\mathrm{P}}\right.$, and $\left.\mathrm{BP} \mathrm{ND}_{\mathrm{ND}}\right)$. However, estimating $\mathrm{BP}_{\mathrm{F}}$ requires measurement of $f_{\mathrm{P}}$, which is particularly low with $\left[{ }^{11} \mathrm{C}\right] \mathrm{WAY}-100635$. When we reanalyzed our data using the outcome measure $\mathrm{BP}_{\mathrm{P}}$
( $=V_{\mathrm{T}}-V_{\mathrm{ND}}=f_{\mathrm{p}} B_{\text {avail }} / K_{\mathrm{D}}$ ), which requires the assumption of equivalent $f_{\mathrm{P}}$ between groups, but which therefore does not require $f_{\mathrm{P}}$ measurement, $5-\mathrm{HT}_{1 \mathrm{~A}} \mathrm{BP}_{\mathrm{P}}$ was numerically higher among remitted depressed subjects than controls (an average of $9.2 \%$ higher across all ROIs), although this difference was not statistically significant. This suggests that the observed difference in $\mathrm{BP}_{\mathrm{F}}$ between groups is partially dependent on $f_{\mathrm{P}}$. We observed lower $f_{\mathrm{P}}$ among remitted depressed subjects than controls; we had previously found non-significantly lower $f_{\mathrm{P}}$ among currently depressed subjects than controls (Parsey et al, 2006d). If such a peripheral marker was found to reliably correlate (inversely) with cerebral $5-\mathrm{HT}_{1 \mathrm{~A}} \mathrm{BP}_{\mathrm{F}}$, it could be used clinically as a less invasive surrogate marker for cerebral $5-\mathrm{HT}_{1 \mathrm{~A}}$ binding. However, there is a significant overlap in $\left[{ }^{11} \mathrm{C}\right] \mathrm{WAY}-100635 f_{\mathrm{P}}$ between groups, and $f_{\mathrm{P}}$ is insensitive to regional heterogeneity in brain receptor binding. Of note, Hirvonen et al (2008) previously compared AN currently depressed subjects with healthy controls using the outcome measure $\mathrm{BP}_{\mathrm{P}}$, reporting lower $5-\mathrm{HT}_{1 \mathrm{~A}} \mathrm{BP}_{\mathrm{P}}$ among currently depressed subjects than controls; that study did not examine remitted depressed subjects. Differences in methodology include their use of atlas-based methods for automated ROI labeling. In addition, it is possible that frequencies of the $\mathrm{C}-1019 \mathrm{G} 5-\mathrm{HT}_{1 \mathrm{~A}}$ receptor polymorphism 
differed between samples, although this was not reported in their study, which may also have contributed to discrepant findings in comparing currently depressed subjects with controls.

Our findings are consistent with broadly distributed elevations in $5-\mathrm{HT}_{1 \mathrm{~A}}$ receptor binding as a trait abnormality in MDD. On the basis of these results, we propose the following model to integrate several recent findings by our group and others regarding longitudinal $5-\mathrm{HT}_{1 \mathrm{~A}}$ expression in major depression (Figure 2). Due to genetics, childhood experiences, or gene-environment interactions, AN subjects with MDD have higher $5-\mathrm{HT}_{1 \mathrm{~A}} \mathrm{BP}_{\mathrm{F}}$ than healthy controls by the time of the onset of a first MDE. If this receptor difference is important causally, one would predict that 5$\mathrm{HT}_{1 \mathrm{~A}}$ receptor differences precede the development of depressive symptomatology, a question for future study. Chronic treatment with antidepressants may then lead to reductions in $5-\mathrm{HT}_{1 \mathrm{~A}} \mathrm{BP}_{\mathrm{F}}$, although data are inconclusive. We find lower 5- $\mathrm{HT}_{1 \mathrm{~A}} \mathrm{BP}_{\mathrm{F}}$ among MDD subjects who have received previous antidepressant treatment compared with medication-naive MDD subjects, providing cross-sectional evidence of medication effects (Parsey et al, 2006d). A reduction in $5-\mathrm{HT}_{1 \mathrm{~A}} \mathrm{BP}_{\mathrm{ND}}$ after $\geqslant 12$ weeks of treatment with escitalopram was reported in subjects with social phobia or panic disorder, indicating receptor downregulation with chronic SSRI use (Spindelegger et al, 2008). Consistent with these human findings, mice that have been stressed by housing in isolation show increased $5-\mathrm{HT}_{1 \mathrm{~A}}$ receptor binding, which is reversed postsynaptically by chronic treatment with the SSRI citalopram (Gunther et al, 2008). In contrast, other human studies have not observed changes in $5-\mathrm{HT}_{1 \mathrm{~A}}$ binding after shorter SSRI courses in major depression (MosesKolko et al, 2007a, Sargent et al, 2000). Finally, we find higher $5-\mathrm{HT}_{1 \mathrm{~A}} \mathrm{BP}_{\mathrm{F}}$ in remitted depressed subjects who were off antidepressant medications for a minimum of 6 months compared with controls, suggesting that $5-\mathrm{HT}_{1 \mathrm{~A}} \mathrm{BP}_{\mathrm{F}}$ increases again over time after stopping antidepressant medication, returning to elevated pre-treatment levels without return of MDE, and that it remains persistently elevated into remission among subjects not taking antidepressant medication.

Trait elevations in $5-\mathrm{HT}_{1 \mathrm{~A}} \mathrm{BP}_{\mathrm{F}}$ in $\mathrm{MDD}$ could be partly explained by a genetic model of overrepresentation of the
$\mathrm{G}$ allele of the $5-H T_{1 A} \mathrm{C}(-1019) \mathrm{G}$ polymorphism among subjects with MDD (Albert, 2004). This would lead to higher $5-\mathrm{HT}_{1 \mathrm{~A}}$ auto-receptor binding in the raphe nucleus (Parsey et al, 2006d), leading to greater inhibition of serotonergic neuronal firing and decreased serotonin release in the terminal field of serotonin neurons, potentially leading to compensatory upregulation of $5-\mathrm{HT}_{1 \mathrm{~A}}$ receptors in the terminal field. Whether less serotonin release related to this polymorphism would result in post-synaptic $5-\mathrm{HT}_{1 \mathrm{~A}}$ receptor upregulation to compensate for serotonergic deficit is not known (Cahir et al, 2007), although a neurodevelopmental model would be required to test this hypothesis thoroughly.

This genetic model is limited, as we did not observe an association between $\mathrm{C}(-1019) \mathrm{G}$ polymorphism and $5-\mathrm{HT}_{1 \mathrm{~A}}$ binding among the modest sample of remitted depressed subjects in this study $(\mathrm{F}=1.34, \mathrm{df}=2.9, p=0.31)$ although such an association was previously observed when considering a larger sample of 42 healthy controls and 28 currently depressed MDD subjects (Parsey et al, 2006d). In addition, many subjects who develop MDD do not carry the $\mathrm{G}$ allele of this polymorphism, and differences in genotype frequency were only significant comparing currently depressed subjects with controls. The fact that allelic frequencies at this locus for remitted depressed subjects were intermediate between healthy controls and currently depressed subjects, but not significantly different from either group, may simply be due to the small size of this sample for genetic studies. Alternatively, although speculative, it is possible that subjects with MDD who achieve sustained remission have a lower frequency of the $\mathrm{G}$ allele compared with other MDD subjects (Le François et al, 2008), predisposing them to a better antidepressant response and to a greater likelihood of sustained remission. Larger sample sizes are clearly needed to test this hypothesis thoroughly.

Although we did not observe region-by-diagnosis interactions when comparing remitted depressed subjects with either controls or AN currently depressed subjects, there are some regions in which remitted depressed $5-\mathrm{HT}_{1 \mathrm{~A}} \mathrm{BP}_{\mathrm{F}}$ appears closer to controls than to AN currently depressed subjects (Figure 1). This suggests the need for replication studies with larger sample sizes to study whether $5-\mathrm{HT}_{1 \mathrm{~A}}$ $\mathrm{BP}_{\mathrm{F}}$ may normalize partially in a regionally specific manner during sustained remission from MDD.

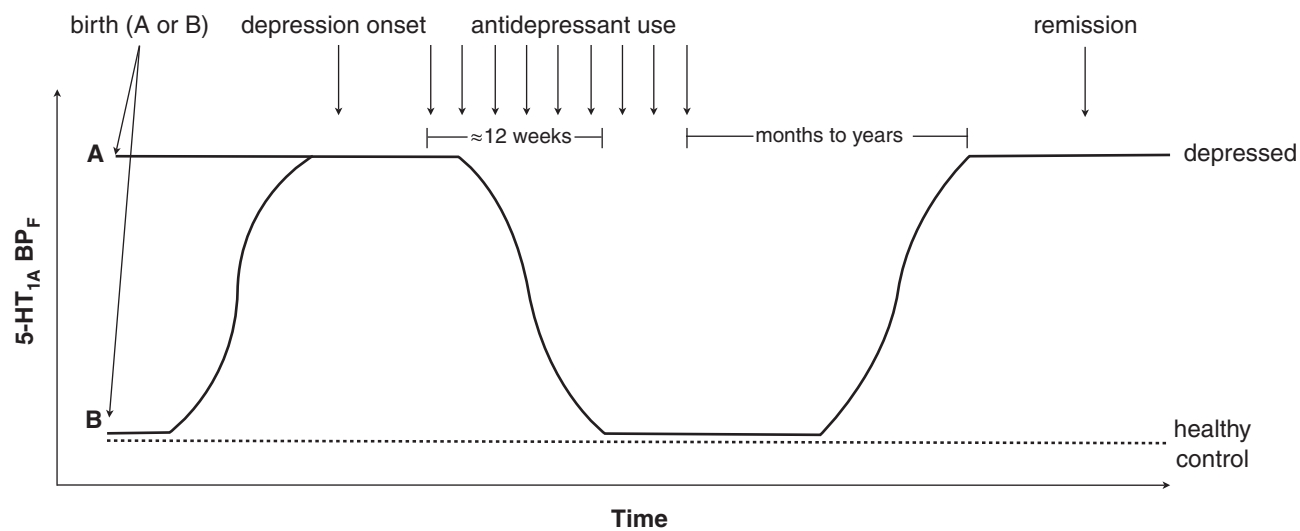

Figure 2 Chronological model of serotonin IA receptor binding potential over the life span among subjects with major depressive disorder compared with healthy controls. 
There were some clinical and demographic differences between groups. Lifetime aggression (which has been associated with $5-\mathrm{HT}_{1 \mathrm{~A}} \mathrm{BP}_{\mathrm{F}}$ ) was higher among remitted depressed subjects than controls. Differences in $5-\mathrm{HT}_{1 \mathrm{~A}} \mathrm{BP}_{\mathrm{F}}$ between remitted depressed and controls remained highly significant after aggression was included as a co-variate. The remitted depressed group had a higher proportion of Caucasian individuals than controls or AN currently depressed subjects, and was more highly educated than the AN currently depressed group. There was also a trend toward a lower unemployment rate among remitted depressed than AN currently depressed subjects (13 vs $50 \%, p=0.08$ ). These factors were all associated with a higher likelihood of remission with citalopram treatment in the STAR ${ }^{\circ}$ trial (Trivedi et al, 2006), consistent with the frequencies observed in our sample. Although we are unaware of any studies reporting differences in $5-\mathrm{HT}_{1 \mathrm{~A}}$ binding as a function of race or ethnicity, group differences in ethnicity may have affected allelic frequencies of the $5-\mathrm{HT}_{1 \mathrm{~A}}$ receptor promoter polymorphism examined. Although not statistically significant, remitted depressed subjects were 6 years younger than healthy controls on average. We and others have previously found no effect of age on 5- $\mathrm{HT}_{1 \mathrm{~A}}$ binding (Parsey et al, 2002; Rabiner et al, 2002a; Sargent et al, 2000). Similarly, we found no correlation between age and 5- $\mathrm{HT}_{1 \mathrm{~A}} \mathrm{BP}_{\mathrm{F}}$ in any region in the current cohort. Although others have described agerelated decline in $5-\mathrm{HT}_{1 \mathrm{~A}}$ binding (Bhagwagar et al, 2004; Cidis Meltzer et al, 2001; Moller et al, 2007; Tauscher et al, 2001), the magnitude of these reported effects is insufficient to explain our findings, given the small difference in age between groups. There was a higher incidence of comorbid anxiety disorders among AN currently depressed subjects compared with remitted depressed subjects. Although panic disorder and social anxiety disorder have been associated with lower $5-\mathrm{HT}_{1 \mathrm{~A}}$ receptor binding (Lanzenberger et al, 2007; Nash et al, 2008; Neumeister et al, 2004), the small number of subjects with these comorbidities in the current sample prevented statistical analysis of such effects.

This study has some limitations. It has a modest sample size of remitted depressed subjects. In addition, remitted depressed subjects reported past antidepressant exposure, but this exposure was on average 3 years earlier, and hence is unlikely to have had persistent effects on $5-\mathrm{HT}_{1 \mathrm{~A}} \mathrm{BP}_{\mathrm{F}}$. Any residual effects of past antidepressant medication on $5-\mathrm{HT}_{1 \mathrm{~A}}$ receptors among remitted depressed subjects would be expected to lead to lower $5-\mathrm{HT}_{1 \mathrm{~A}} \mathrm{BP}_{\mathrm{F}}$ (Parsey et al, 2006d), and thereby to an underestimation of the magnitude of the difference we report between remitted depressed subjects and healthy controls. Remitted depressed subjects were recruited once they were already in sustained remission; their clinical history was therefore based on subjects' retrospective reports of previous depressive episodes and symptoms. Future studies could identify subjects prospectively by following-up individuals assessed during a current MDE into periods of sustained remission. Finally, PET data from some healthy controls and all AN depressed subjects in comparator groups were collected from a previous study (Parsey et al, 2006d). This is unlikely to have influenced the results reported in this study, as PET acquisition, processing, and data analysis did not differ between groups. There was no difference in $5-\mathrm{HT}_{1 \mathrm{~A}} \mathrm{BP}_{\mathrm{F}}$ between the first and second cohorts of controls, making temporal drift an unlikely explanation of our findings. Although $T_{1}$-weighted MRIs used for identification of ROIs were performed on 1.5 and $3 \mathrm{~T}$ cameras, we observed no difference in the volume of a representative ROI, the dorsolateral PFC, as a function of MRI camera (comparison among remitted depressed: $t=0.90, \mathrm{df}=13, p=0.38$; comparison among healthy controls: $t=1.08, \mathrm{df}=49$, $p=0.29)$. Similarly, regional $\left[{ }^{11} \mathrm{C}\right] \mathrm{WAY}-100635 V_{\mathrm{T}}$ values did not differ as a function of MRI camera when comparing age- and sex- matched controls considering all ROIs $(\mathrm{F}=0.004, \mathrm{df}=1,11.87, p=0.95)$.

$5-\mathrm{HT}_{1 \mathrm{~A}} \mathrm{BP}_{\mathrm{F}}$ may serve as a biological marker in populations at risk for the development of MDD (including those with a family history of mood disorder), which could be used for the purposes of screening and primary prevention. Future studies should examine genetic and non-genetic causes of elevated $5-\mathrm{HT}_{1 \mathrm{~A}}$ receptor $\mathrm{BF}_{\mathrm{F}}$ in MDD, its relationship to treatment outcome, and the effect of treatment on binding.

In summary, this study provides evidence of persistently elevated $5-\mathrm{HT}_{1 \mathrm{~A}}$ receptor $\mathrm{BP}$ F among subjects with MDD in sustained remission, consistent with a trait serotonergic abnormality in MDD. Apparent discrepancies between this finding and previously published findings are reconciled through a close analysis of PET acquisition and analysis methodologies.

\section{ACKNOWLEDGEMENTS}

We would like to thank Dr Matthew S. Milak, the staff of the Brain Imaging Division and Clinical Evaluation Core of The Department of Molecular Imaging and Neuropathology, as well as the Kreitchman PET Center. Funding for this study was provided by NIMH Grants MH01997-05 and MH4069517 , as well as NARSAD.

\section{DISCLOSURE/CONFLICT OF INTEREST}

Dr Miller has received financial compensation for psychiatric evaluations of subjects enrolled in medication studies sponsored by Pfizer and Orexigen Therapeutics, unrelated to this paper.

Ms Brennan reports no biomedical financial interests or potential conflicts of interest.

Dr Ogden reports no biomedical financial interests or potential conflicts of interest.

Dr Oquendo received financial compensation from Pfizer for the safety evaluation of a clinical facility, and was the recipient of a grant from Eli Lilly to support a year of salary for the Lilly Suicide Scholar, Enrique Baca-Garcia, MD, $\mathrm{PhD}$, both unrelated to this paper.

Dr Sullivan has been on speakers' bureaus for Pfizer and GSK, has consulted for Jazz Pharmaceuticals and Krele Pharmaceuticals, previously owned stock in Pfizer, and has a patent application for use of tianeptine, all unrelated to this paper.

Dr Mann is the principal investigator on PET Imaging grants from GSK and Novartis unrelated to this paper. 
Dr Parsey has received PET Imaging grants from Novartis Pharmaceuticals, Sepracor, Inc., Pfizer, and Eli Lilly Company, unrelated to this paper.

\section{REFERENCES}

Aghajanian GK, Sanders-Bush E (2002). Serotonin. In: Davis KL, Charney D, Coyle JT, Nemeroff C (eds) Neuropsychopharmacology - The Fifth Generation of Progress. Lipincott Williams \& Wilkins: Philadelphia. pp 15-34.

Albert PR (2004). A functional promoter polymorphism of the 5HT1A receptor gene: association with depression and completed suicide. Biol Psychiatry 55: 46S.

Ashburner J, Friston KJ (1999). Nonlinear spatial normalization using basis functions. Hum Brain Mapp 7: 254-266.

Ashburner J, Friston KJ (2005). Unified segmentation. Neuroimage 26: 839-851.

Basso MR, Bornstein RA (1999). Relative memory deficits in recurrent versus first-episode major depression on a word-list learning task. Neuropsychology 13: 557-563.

Beck AT, Ward CH, Mendelson M, Mock J, Erbauh J (1961). An inventory for measuring depression. Arch Gen Psychiatry 4: 53-63.

Beck AT, Weissman A, Lester D, Trexler L (1974). The measurement of pessimism: the hopelessness scale. J Consult Clin Psychol 42: 861-865.

Bhagwagar Z, Cowen PJ (2008). 'It s not over when it's over': persistent neurobiological abnormalities in recovered depressed patients. Psychol Med 38: 307-313.

Bhagwagar Z, Rabiner EA, Sargent PA, Grasby PM, Cowen PJ (2004). Persistent reduction in brain serotonin1A receptor binding in recovered depressed men measured by positron emission tomography with [11C]WAY-100635. Mol Psychiatry 9: 386-392.

Bhagwagar Z, Whale R, Cowen PJ (2002). State and trait abnormalities in serotonin function in major depression. $\mathrm{Br} \mathrm{J}$ Psychiatry 180: 24-28.

Boldrini M, Underwood MD, Mann JJ, Arango V (2008). Serotonin$1 \mathrm{~A}$ autoreceptor binding in the dorsal raphe nucleus of depressed suicides. J Psychiatr Res 42: 433-442.

Brix G, Zaers J, Adam LE, Bellemann ME, Ostertag H, Trojan H et al. (1997). Performance evaluation of a whole-body PET scanner using the NEMA protocol National Electrical Manufacturers Association. J Nucl Med 38: 1614-1623.

Cahir M, Ardis T, Reynolds GP, Cooper SJ (2007). Acute and chronic tryptophan depletion differentially regulate central 5-HT1A and 5-HT 2A receptor binding in the rat. Psychopharmacology 190: 497-506.

Cidis Meltzer C, Drevets WC, Price JC, Mathis CA, Lopresti B, Greer PJ et al. (2001). Gender-specific aging effects on the serotonin 1A receptor. Brain Res 895: 9-17.

Drevets WC, Frank E, Price JC, Kupfer DJ, Holt D, Greer PJ et al. (1999). PET imaging of serotonin 1A receptor binding in depression. Biol Psychiatry 46: 1375-1387.

Drevets WC, Thase ME, Moses-Kolko EL, Price J, Frank E, Kupfer DJ et al. (2007). Serotonin-1A receptor imaging in recurrent depression: replication and literature review. Nucl Med Biol 34: 865-877.

Duvernoy H (1991). The Human Brain Surface, Three-Dimensional Sectional Anatomy and MRI. Sringer-Verlag Wien: New York.

Endicott J, Spitzer RL, Fleiss JL, Cohen J (1976). The global assessment scale. A procedure for measuring overall severity of psychiatric disturbance. Arch Gen Psychiatry 33: 766-771.

First M, Spitzer R, Gibbon M, Williams J (1995). Structured Clinical Interview for DSM-IV Axis I Disorders (SCID-I/P, Version 2.0). Biometrics Research Dept. New York State Psychiatric Institute: New York.
Flory JD, Mann JJ, Manuck SB, Muldoon MF (1998). Recovery from major depression is not associated with normalization of serotonergic function. Biol Psychiatry 43: 320-326.

Gunther L, Liebscher S, Jahkel M, Oehler J (2008). Effects of chronic citalopram treatment on 5-HT(1A) and 5-HT(2A) receptors in group- and isolation-housed mice. Eur J Pharmacol 593: 49-61 (e-pub 11 July 2008).

Hamilton M (1960). A rating scale for depression. J Neurol Neurosurg Psychiatr 23: 56-62.

Hirvonen J, Karlsson H, Kajander J, Lepola A, Markkula J, RasiHakala H et al. (2008). Decreased brain serotonin 5-HT1A receptor availability in medication-naive patients with major depressive disorder: an in-vivo imaging study using PET and [carbonyl11C]WAY-100635. Int J Neuropsychopharmacol 11: 465-476.

Jenkinson M, Smith S (2001). A global optimisation method for robust affine registration of brain images. Med Image Anal 5: 143-156.

Jindal RD, Thase ME, Fasiczka AL, Friedman ES, Buysse DJ, Frank E et al. (2002). Electroencephalographic sleep profiles in singleepisode and recurrent unipolar forms of major depression: II Comparison during remission. Biol Psychiatry 51: 230-236.

Kates WR, Abrams MT, Kaufmann WE, Breiter SN, Reiss AL (1997). Reliability and validity of MRI measurement of the amygdala and hippocampus in children with fragile $\mathrm{X}$ syndrome. Psychiat Res Neuroimag 75: 31-48.

Killiany RJ, Moss MB, Nicholson T, Jolesz F, Sandor T (1997). An interactive procedure for extracting features of the brain from magnetic resonance images: the lobes. Hum Brain Mapp 5: 355-363.

Kupfer DJ, Ehlers CL, Frank E, Grochocinski VJ, McEachran AB (1991). EEG sleep profiles and recurrent depression. Biol Psychiatry 30: 641-655.

Lammertsma AA, Hume SP (1996). Simplified reference tissue model for PET receptor studies. Neuroimage 4: 153-158.

Lanzenberger RR, Mitterhauser M, Spindelegger C, Wadsak W, Klein N, Mien LK et al. (2007). Reduced serotonin-1A receptor binding in social anxiety disorder. Biol Psychiatry 61: 1081-1089.

Laruelle M, van Dyck C, Abi-Dargham A, Zea-Ponce Y, Zoghbi SS, Charney DS et al. (1994). Compartmental modeling of iodine123-iodobenzofuran binding to dopamine D2 receptors in healthy subjects. J Nucl Med 35: 743-754.

Le François B, Czesak M, Steubl D, Albert PR (2008). Transcriptional regulation at a HTR1A polymorphism associated with mental illness. Neuropharmacology 55: 977-985.

Lemonde S, Turecki G, Bakish D, Du L, Hrdina PD, Bown CD et al. (2003). Impaired repression at a 5-hydroxytryptamine $1 \mathrm{~A}$ receptor gene polymorphism associated with major depression and suicide. J Neurosci 23: 8788-8799.

Meltzer CC, Price JC, Mathis CA, Butters MA, Ziolko SK, MosesKolko E et al. (2004). Serotonin 1A receptor binding and treatment response in late-life depression. Neuropsychopharmacology 29: 2258-2265.

Miller JM, Oquendo MA, Ogden RT, Mann JJ, Parsey RV (2008). Serotonin transporter binding as a possible predictor of oneyear remission in major depressive disorder. J Psychiatr Res 42: 1137-1144.

Mintun MA, Raichle ME, Kilbourn MR, Wooten GF, Welch MJ (1984). A quantitative model for the in vivo assessment of drug binding sites with positron emission tomography. Ann Neurol 15: $217-227$.

Moller M, Jakobsen S, Gjedde A (2007). Parametric and regional maps of free serotonin 5HT1A receptor sites in human brain as function of age in healthy humans. Neuropsychopharmacology 32: $1707-1714$.

Moses-Kolko EL, Price JC, Thase ME, Meltzer CC, Kupfer DJ, Mathis CA et al. (2007a). Measurement of 5-HT1A receptor binding in depressed adults before and after antidepressant drug treatment using positron emission tomography and [11C]WAY100635. Synapse 61: 523-530. 
Moses-Kolko EL, Wisner KL, Price JC, Berga SL, Drevets WC, Hanusa BH et al. (2007b). Serotonin 1A receptor reductions in postpartum depression: a positron emission tomography study. Fertil Steril.

Nash JR, Sargent PA, Rabiner EA, Hood SD, Argyropoulos SV, Potokar JP et al. (2008). Serotonin 5-HT1A receptor binding in people with panic disorder: positron emission tomography study. Br J Psychiatry 193: 229-234.

Naudon L, El Yacoubi M, Vaugeois JM, Leroux-Nicollet I, Costentin J (2002). A chronic treatment with fluoxetine decreases 5-HT(1A) receptors labeling in mice selected as a genetic model of helplessness. Brain Res 936: 68.

Navines R, Gomez-Gil E, Martin-Santos R, de Osaba MJ, Escolar G, Gasto C (2007). Hormonal response to buspirone is not impaired in major depression. Hum Psychopharmacol 22: 389-395.

Neumeister A, Bain E, Nugent AC, Carson RE, Bonne O, Luckenbaugh DA et al. (2004). Reduced serotonin type 1A receptor binding in panic disorder. J Neurosci 24: 589-591.

Ogden RT, Tarpey T (2006). Estimation in regression models with externally estimated parameters. Biostatistics (Oxford, England) 7: 115-129.

Oquendo MA, Hastings RS, Huang YY, Simpson N, Ogden RT, Hu $\mathrm{XZ}$ et al. (2007). Brain serotonin transporter binding in depressed patients with bipolar disorder using positron emission tomography. Arch Gen Psychiatry 64: 201-208.

Parsey RV, Arango V, Olvet DM, Oquendo MA, Van Heertum RL, John Mann J (2005a). Regional heterogeneity of 5-HT1A receptors in human cerebellum as assessed by positron emission tomography. J Cereb Blood Flow Metab 25: 785-793.

Parsey RV, Belanger MJ, Sullivan GM, Simpson NR, Stabin MG, Van Heertum $\mathrm{R}$ et al. (2005b). Biodistribution and radiation dosimetry of 11C-WAY100,635 in humans. J Nucl Med 46: 614-619.

Parsey RV, Hastings RS, Oquendo MA, Hu X, Goldman D, Huang YY et al. (2006a). Effect of a triallelic functional polymorphism of the serotonin-transporter-linked promoter region on expression of serotonin transporter in the human brain. Am J Psychiatry 163: 48-51.

Parsey RV, Hastings RS, Oquendo MA, Huang YY, Simpson N, Arcement J (2006b). Lower serotonin transporter binding potential in the human brain during major depressive episodes. Am J Psychiatry 163: 52-58.

Parsey RV, Olvet DM, Oquendo MA, Huang YY, Ogden RT, Mann JJ (2006c). Higher 5-HT1A receptor binding potential during a major depressive episode predicts poor treatment response: preliminary data from a naturalistic study. Neuropsychopharmacology 31: 1745-1749.

Parsey RV, Oquendo MA, Ogden RT, Olvet DM, Simpson N, Huang YY et al. (2006d). Altered serotonin 1A binding in major depression: a [carbonyl-C-11]WAY100635 positron emission tomography study. Biol Psychiatry 59: 106-113.

Parsey RV, Oquendo MA, Simpson NR, Ogden RT, Van Heertum R, Arango $\mathrm{V}$ et al. (2002). Effects of sex, age, and aggressive traits in man on brain serotonin 5-HT(1A) receptor binding potential measured by PET using [C-11]WAY-100635. Brain Res 954: 173-182.

Parsey RV, Slifstein M, Hwang DR, Abi-Dargham A, Simpson N, Mawlawi $\mathrm{O}$ et al. (2000). Validation and reproducibility of measurement of 5-HT1A receptor parameters with [carbonyl11C]WAY-100635 in humans: comparison of arterial and reference tisssue input functions. J Cereb Blood Flow Metab 20: 1111-1133.

Rabiner EA, Messa C, Sargent PA, Husted-Kjaer K, Montgomery A, Lawrence AD et al. (2002a). A database of [(11)C]WAY-100635 binding to $5-\mathrm{HT}(1 \mathrm{~A})$ receptors in normal male volunteers: normative data and relationship to methodological, demographic, physiological, and behavioral variables. Neuroimage 15: 620-632.

Rabiner EA, Wilkins MR, Turkheimer F, Gunn RN, Udo de Haes J, de Vries $M$ et al. (2002b). 5-HydroxytryptaminelA receptor occupancy by novel full antagonist 2-[4-[4-(7-chloro-2,3-dihydro-1,4-benzdioxyn-5-yl)-1-piperazinyl]butyl]-1,2-benzi sothiazol-3-(2H)-one-1, 1-dioxide: a[11C][O-methyl-3H]-N-(2-(4-(2-methoxyphenyl)-1piperazinyl)ethyl)-N-(2-pyridinyl)cyclohexanecarboxamide trihydrochloride (WAY-100635) positron emission tomography study in humans. J Pharmacol Exp Ther 301: 1144-1150.

Ruhe HG, Mason NS, Schene AH (2007). Mood is indirectly related to serotonin, norepinephrine and dopamine levels in humans: a meta-analysis of monoamine depletion studies. Mol Psychiatry 12: 331-359.

Sargent PA, Kjaer KH, Bench CJ, Rabiner EA, Messa C, Meyer J et al. (2000). Brain serotonin1A receptor binding measured by positron emission tomography with [11C]WAY-100635: effects of depression and antidepressant treatment. Arch Gen Psychiatry 57: 174-180.

Shively CA, Friedman DP, Gage HD, Bounds MC, Brown-Proctor C, Blair JB et al. (2006). Behavioral depression and positron emission tomography-determined serotonin $1 \mathrm{~A}$ receptor binding potential in cynomolgus monkeys. Arch Gen Psychiatry 63: 396-403.

Shively CA, Willard SL, Davenport A, Friedman DP (2007). 5HT1a receptor binding in the hippocampus of behaviorally depressed female cynomolgus macaques (Macaca fascicularis). Soc Neurosci.

Slifstein M, Laruelle M (2001). Models and methods for derivation of in vivo neuroreceptor parameters with PET and SPECT reversible radiotracers. Nucl Med Biol 28: 595-608.

Slifstein M, Parsey RV, Laruelle M (2000). Derivation of [(11)C]WAY-100635 binding parameters with reference tissue models: effect of violations of model assumptions [In Process Citation]. Nucl Med Biol 27: 487-492.

Smith SM (2002). Fast robust automated brain extraction. Hum Brain Mapp 17: 143-155.

Spindelegger C, Lanzenberger R, Wadsak W, Mien LK, Stein P et al. (2008). Influence of escitalopram treatment on 5-HT1A receptor binding in limbic regions in patients with anxiety disorders. Mol Psychiatry.

Stockmeier CA (2003). Involvement of serotonin in depression: evidence from postmortem and imaging studies of serotonin receptors and the serotonin transporter. J Psychiatr Res 37: 357-373.

Sullivan GM, Oquendo MA, Simpson N, Van Heertum RL, Mann JJ, Parsey RV (2005). Brain serotonin1A receptor binding in major depression is related to psychic and somatic anxiety. Biol Psychiatry 58: 947-954.

Talairach J, Tournoux P (1988). Co-planar Stereotactic Atlas of the Human Brain Three-Dimensional Proportional System: An Approach of Cerebral Imaging. Theime Medical Publisher: New York.

Tauscher J, Verhoeff NP, Christensen BK, Hussey D, Meyer JH, Kecojevic A et al. (2001). Serotonin 5-HT1A receptor binding potential declines with age as measured by [11C]WAY-100635 and PET. Neuropsychopharmacology 24: 522-530.

Thase ME (1992). Long-term treatments of recurrent depressive disorders. J Clin Psychiatry 53: Suppl:32-Suppl:44.

Thase ME, Kupfer DJ, Buysse DJ, Frank E, Simons AD, McEachran $\mathrm{AB}$ et al. (1995). Electroencephalographic sleep profiles in single-episode and recurrent unipolar forms of major depression: I Comparison during acute depressive states. Biol Psychiatry 38: 506-515.

Trivedi MH, Rush AJ, Wisniewski SR, Nierenberg AA, Warden D, Ritz L et al. (2006). Evaluation of outcomes with citalopram for depression using measurement-based care in $\mathrm{STAR}^{*} \mathrm{D}$ : implications for clinical practice. Am J Psychiatry 163: 28-40.

Watson CC, Newport D, Casey ME (1995). A single scatter simulation technique for scatter correction in 3D PET. Proceedings of the 3rd International Meeting on Fully Three-Dimensional Image Reconstruction in Radiology and Nuclear Medicine. Aix-les-bains, France, pp 215-219. 